\title{
Familial Mediterranean fever seems to be not uncommon in Greece
}

\author{
European Journal of Human Genetics (2004) 12, 85-86. doi:10.1038/sj.ejhg.5201096 \\ Published online 3 December 2003
}

We like to share some thoughts of our FMF Group in Athens on the paper by M La Regina et $a l^{1}$ on Familial Mediterranean fever (FMF) in Italy, which may further contribute to a better understanding of the distribution of the disease in Mediterranean countries.

Although Greek patients are already included in very early descriptions of $\mathrm{FMF}^{2}$ its population epidemiology has not been studied systematically in the country. The absence of confirmatory method(s) before pyrin gene cloning may have been a contributing factor.

In studies of our group, mainly based on molecular testing of suspected-referred cases, it seems that FMF underdiagnosis in this country cannot be excluded. The preliminary results of our work are already published. $^{3}$ Briefly, it seems that FMF mutation is a rather common genetic feature in the Greek population. If we take into account that apart from the 'genuine' Greek population important genetic influences are also expected from populations from surrounding areas (Turkey, Israel, Arab countries), and also that important immigrations to Greece took place in historical times (Armenians), the disease must be considered no longer as 'rare' in Greece. This must be emphasized during academic and professional training of Greek doctors as well.

La Regina et al ${ }^{1}$ point out that most of their cases come from the so-called 'Magna Grecia' regions of Italy, an area originally inhabited to a great extent by populations of Greek ancestry. This observation fits well with another observation of one of us, on the distribution of HLA-A and -B genes within Greece and surrounding countries, including Italy. ${ }^{4}$ According to this observation, the 'Magna Grecia' populations of Italy seem to share common genetic markers with those of the Southern Greece. If this is the case for HLA genes, it may apply for FMF mutations as well.

The frequency of particular FMF mutations among Greeks and Italians points out that no important deviations from the 'endemic' populations are noted. However, we also note a rather high percentage of unknown FMF mutations among Greeks as in Italians.
We would also like to emphasize a few more points:

(i) In our study, we found some FMF cases in the socalled Roman-Jews of Greece, a small Jewish tribe (not to be confused with the Roman Jews of Rome) dating here to Classical Times many centuries before the Grand Exile of Jews from Spain to Greece in Medieval Ages. To the best of our knowledge, it is the first time FMF is found in Roman Jews of Greece.

(ii) The terminology referring to the national origin of FMF cases needs standardization. It is our impression that at least some so-called 'Greek' cases sporadically reported in the literature thus far, in fact refer to Arabs from Syria who are Greek-Orthodox in religion, but not 'Greeks' (PN Hawkins, personal communication). Obviously, this can lead to miscalculations in the frequency of particular mutations.

(iii) Many cases in our study seem to come from Rhodes island, that is the southest part of Greece, close to Asia Minor and Cyprus. Cyprus is a seemingly 'rich' FMF area, inhabited by a population of indisputable Greek origin, with heterozygote frequency one in $25 .^{5}$ Although a population study is not available yet, it is anticipapted that a similar frequency exists in mainland Greece as well.

(iv) As opposed to La Regina et al, we have already documented two cases of FMF-Phenotype II in Greeks. ${ }^{6,7}$ A more systematic survey may reveal more such cases, in otherwise 'unexplained' amyloidosis patients.

As misdiagnosis and delay in diagnosis of FMF was very probable before molecular era, the establishment of a systematic network on FMF Survey in European/Mediterranean countries is now emerging. The need for a better understanding of FMF population epidemiology further supports the necessity for global project(s) on genetic diversity. ${ }^{8}$

Kostas Konstantopoulos and Alexandra Kanta University of Athens School of Medicine, First Department of Internal Medicine at Laikon Hospital, Athens-11527, Greece E-mail: kkonstan@med.uoa.gr 
5 Constantinou Deltas C, Mean C, Rossou R et al.: Familial Mediterranean fever (FMF) is a frequent disease in the Greek-Cypriot population of Cyprus. Genetic Testing 2002; 6: $15-21$.

References

1 La Regina M, Nucera G, Diaco M et al.: Familial Mediterranean fever is no longer a rare disease in Italy. Eur J Hum Genet 2003; 11: 50-56.

2 Eliakim M, Levy M, Heller H: Recurrent polyserositis (Familial Mediterranean fever, periodic disease). Amsterdam: Elsevier/NorthHolland Biomedical Press; 1985, pp 5-6.

3 Konstantopoulos K, Kanta A, Deltas C et al.: Familial Mediterranean fever (FMF) associated pyrin mutations in Greece. Ann Reum Dis 2003; 62: 479-481.

4 Konstantopoulos K, Sourdis J: The distribution of HLA-A and-B antigens among populations in the major Balkan area. Int $J$ Anthropol 2001; 16: 245-248.

6 Konstantopoulos K, Michael S, Kanta A et al.: Renal amyloidosis as a first manifestation of Familial Mediterranean fever. Scand ) Rheumatol 2000; 29: 129-130.

7 Konstantopoulos K, Kanta A, Tzoulianos M et al.: Familial Mediterranean fever phenotype II in Greece. Isr Med Assoc J 2001; 3: 862-863.

8 Cavalli-Sforza LL, Bodmer W, Dausset J: Support for genetic diversity project. Nature 1997; 390: 221. 